\title{
Pseudoaneurysm following hamstring tendon harvest in arthroscopic anterior cruciate ligament reconstruction: a case report
}

\author{
Chung-Wei Ho ${ }^{1,2}$, Shih-Han Lee ${ }^{1,2}$, Shen-Han Wu ${ }^{1,2}$, Chun-Yu Lin ${ }^{3,4}$, Chian-Her Lee ${ }^{1,2}$ and Jia-Lin Wu , $^{1,2^{*}}$
}

\begin{abstract}
Background: Vascular injury is a very rare complication following arthroscopic knee surgery. This is the first report of pseudoaneurysm at the saphenous branch of the descending genicular artery complicating semitendinosus tendon harvest in arthroscopic anterior cruciate ligament reconstruction.

Case presentation: A 19-year-old male had developed large ecchymosis, focal swelling and tenderness around his posteromedial knee after an arthroscopic anterior cruciate ligament reconstruction. Compartment syndrome of the lower leg and deep vein thrombosis were ruled out. A pseudoaneurysm formation was confirmed through an angiography and coil embolization was performed. At one year follow up, the patient reported improved functional outcome with good stability of the knee. However, mild paresthesia over the posteromedial calf was noted due to the compression injury of the saphenous nerve by the hematoma.

Conclusions: The pseudoaneurysm was presumed to result from accidental vascular injury while dissecting the accessory bands of the semitendinosus and was successfully treated by coil embolization. Care must be taken to section the expansions of the hamstring tendon, especially when the patient presents with underlying coagulopathy or vascular disease.
\end{abstract}

Keywords: ACL reconstruction, Case report, Complication, Hamstring tendon harvest, Pseudoaneurysm

\section{Background}

Isolated anterior cruciate ligament $(\mathrm{ACL})$ tears are one of the most common orthopedic injuries, with an annual incidence of 68.6 per 100,000 person-years [1]. Surgery is recommended for young active patients who have a high predicted risk of recurrent instability and for individuals of all ages with demonstrated recurrent instability [2].

\footnotetext{
* Correspondence: tmu.sportsmedicine@gmail.com

${ }^{1}$ Department of Orthopedics, School of Medicine, College of Medicine, Taipei Medical University, Taipei, Taiwan

${ }^{2}$ Department of Orthopedics, Taipei Medical University Hospital, Taipei,

Taiwan

Full list of author information is available at the end of the article
}

Arthroscopic reconstruction of the ACL alone accounts for 75,000 cases per year in the United States [3]. Vascular injuries following this surgery are especially rare and account for of $<1 \%$ of all presented complications [4]. In this paper, we report on the first case of pseudoaneurysm occurring at the saphenous branch of descending genicular artery after arthroscopic ACL reconstruction by using the semitendinosus autograft and single-tunnel technique.

\section{Case presentation}

A 19-year old male had a twisting injury to his left knee with a popping sensation when landing during a basketball game. The patient was otherwise healthy, but his history

(c) The Author(s). 2020 Open Access This article is licensed under a Creative Commons Attribution 4.0 International License, which permits use, sharing, adaptation, distribution and reproduction in any medium or format, as long as you give appropriate credit to the original author(s) and the source, provide a link to the Creative Commons licence, and indicate if changes were made. The images or other third party material in this article are included in the article's Creative Commons licence, unless indicated otherwise in a credit line to the material. If material is not included in the article's Creative Commons licence and your intended use is not permitted by statutory regulation or exceeds the permitted use, you will need to obtain permission directly from the copyright holder. To view a copy of this licence, visit http://creativecommons.org/licenses/by/4.0/. The Creative Commons Public Domain Dedication waiver (http://creativecommons.org/publicdomain/zero/1.0/) applies to the data made available in this article, unless otherwise stated in a credit line to the data. 
was notable for epistaxis lasting more than $30 \mathrm{~min}$ since he was 4 years old. This had been evaluated by an otolaryngologist without abnormality and there was no family history of bleeding or clotting disorder. A coagulation test revealed normal prothrombin time (13.4 s; reference interval: $11.0-14.5 \mathrm{~s}$ ), international normalized ratio (1.05) and activated partial thromboplastin time $(40.7 \mathrm{~s}$; reference interval: 32.0-45.1 s). Physical examination including Lachman test, anterior drawer, and pivot shift indicated an acute ACL injury and an MRI confirmed the diagnosis without concomitant injuries. An arthroscopically assisted ACL reconstruction with hamstring tendon autograft was delayed approximately 1 month to allow swelling to subside and to regain range of motion.

A tourniquet was inflated to $280 \mathrm{mmHg}$ prior to the surgery. A longitudinal 3-cm incision for the harvest was made $2 \mathrm{~cm}$ medial to the medial edge of the tibial tubercle, centered over the palpable pes tendons. The distal end of the semitendinosus was whipstitched with no. 2 sutures (Ethibond, Ethicon, Somerville, NJ, USA) and detached from tibia. When releasing expansions of the semitendinosus tendon, the scissors were remained opened and pushed proximally to avoid accidental cutting of the tendon tissue. We performed circumferential palpation around tendons to confirm full release. A closed end tendon stripper is then passed with slow steady force in line with the tendon's trajectory with the knee flexed. The graft is carefully moved from the harvest site to the back table for graft preparation. A twoportal arthroscopic technique was performed with independent tibial and femoral tunnel drilling. The 4-strand hamstring graft was secured with an endobutton on the femur and Bioscrew on the tibia. Hemostasis was achieved throughout the procedure. After incision closure, the tourniquet was deflated without abnormal bleeding being noted and the tourniquet time was 105 min. He was then discharged uneventfully.

Large ecchymosis around his posteromedial knee with focal swelling and tenderness was observed on the sixth postoperative day at the outpatient department. He reported no throbbing pain or pulsatile mass. Physical examination revealed intact distal pulses and there was no pain on passive stretching of his ankle. Deep vein thrombosis was ruled out by a negative D-dimer test and Doppler ultrasound image. Bleeding or a pseudoaneurysm formation within the sartorius was impressed on the computed tomography image (Fig. 1).

Due to the persistent symptoms, he was readmitted to our ward for further management (Fig. 2). A repeated Doppler ultrasound showed a compressible pseudoaneurysm over the posteromedial aspect of the knee (Fig. 3). It was confirmed at the saphenous branch of the descending genicular artery in angiography (Fig. 4). Coil embolization was chosen over open ligation or excision
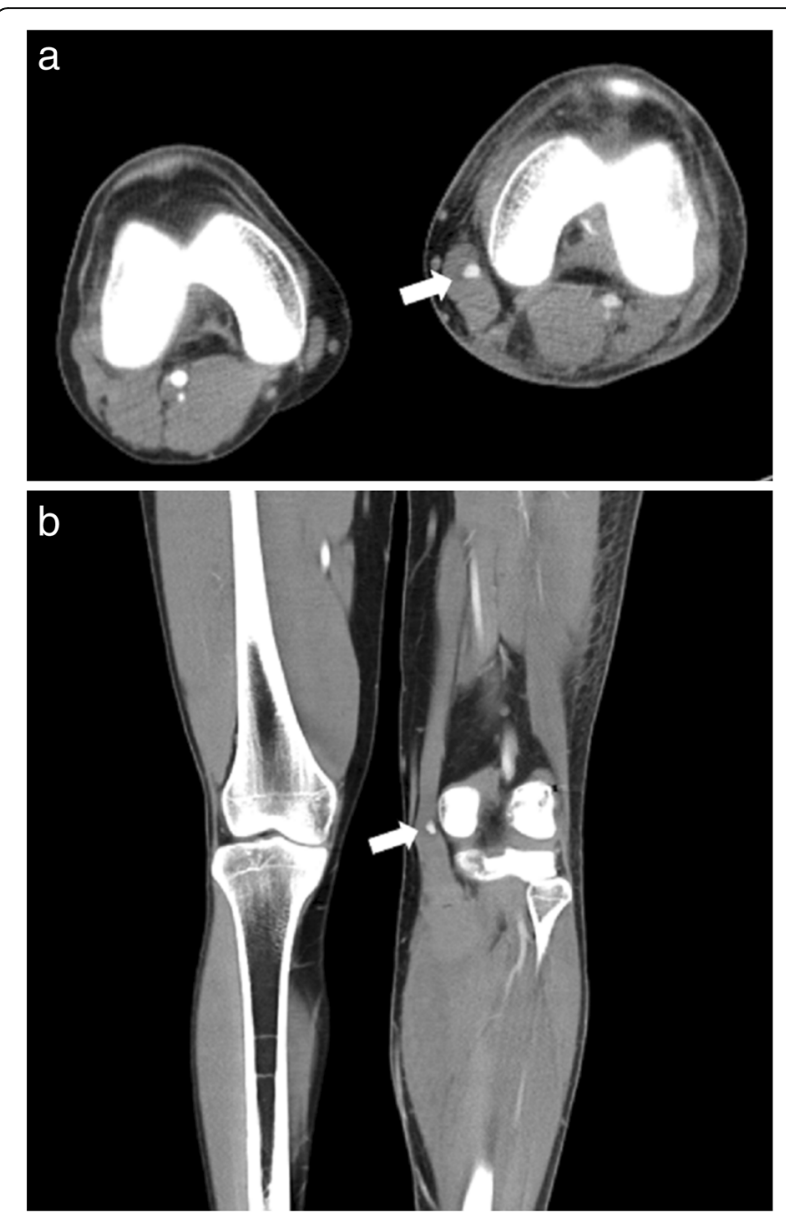

Fig. 1 Computed tomography angiography of the lower limbs. a Axial view and $\mathbf{b}$ coronal view showed intramuscular hematoma and unusual focal contrast enhancement (white arrows) within the sartorius

due to the terminality of this arteriole. Devascularization of the pseudoaneurysm was achieved by placement of two micro-coils (TORNADO 3-2 mm; Cool Medical; Fig. 5). Open debridement with drainage through a new $1-\mathrm{cm}$ incision centered over the ecchymosis was then performed and $600 \mathrm{~mL}$ of hematoma was removed.

No sign of arterial insufficiency or edema was observed after the procedure. At 1 year follow up, the International Knee Documentation Committee Subjective Knee Form score had improved from 6.9 preoperatively to 66.7, and the stability recovered well with negative Lachman and pivot shift tests. He has continued to play basketball recreationally. Mild paresthesia over the posteromedial calf was noted due to the compression injury of the saphenous nerve by the hematoma.

\section{Discussion and conclusions}

According to the few reports on pseudoaneurysm following arthroscopic ACL reconstruction with hamstring 


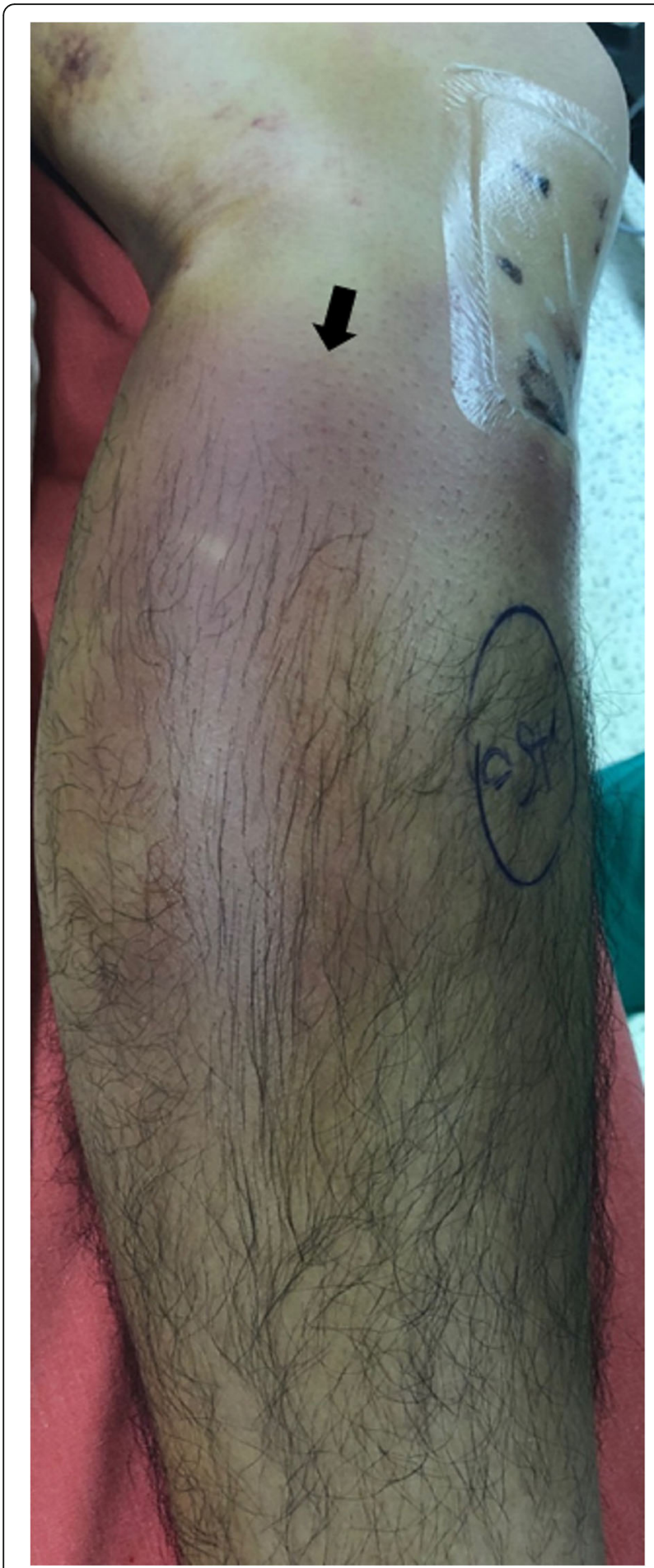

Fig. 2 Appearance of the left knee upon readmission. Large ecchymosis (black arrow) with focal swelling and tenderness persisted at the posteromedial calf postoperatively

tendon autograft, popliteal artery is the most frequently injured vessel [5-8]. Sporadic vascular injuries were also found at different small branches including the articular branch of the descending genicular artery, the perforating
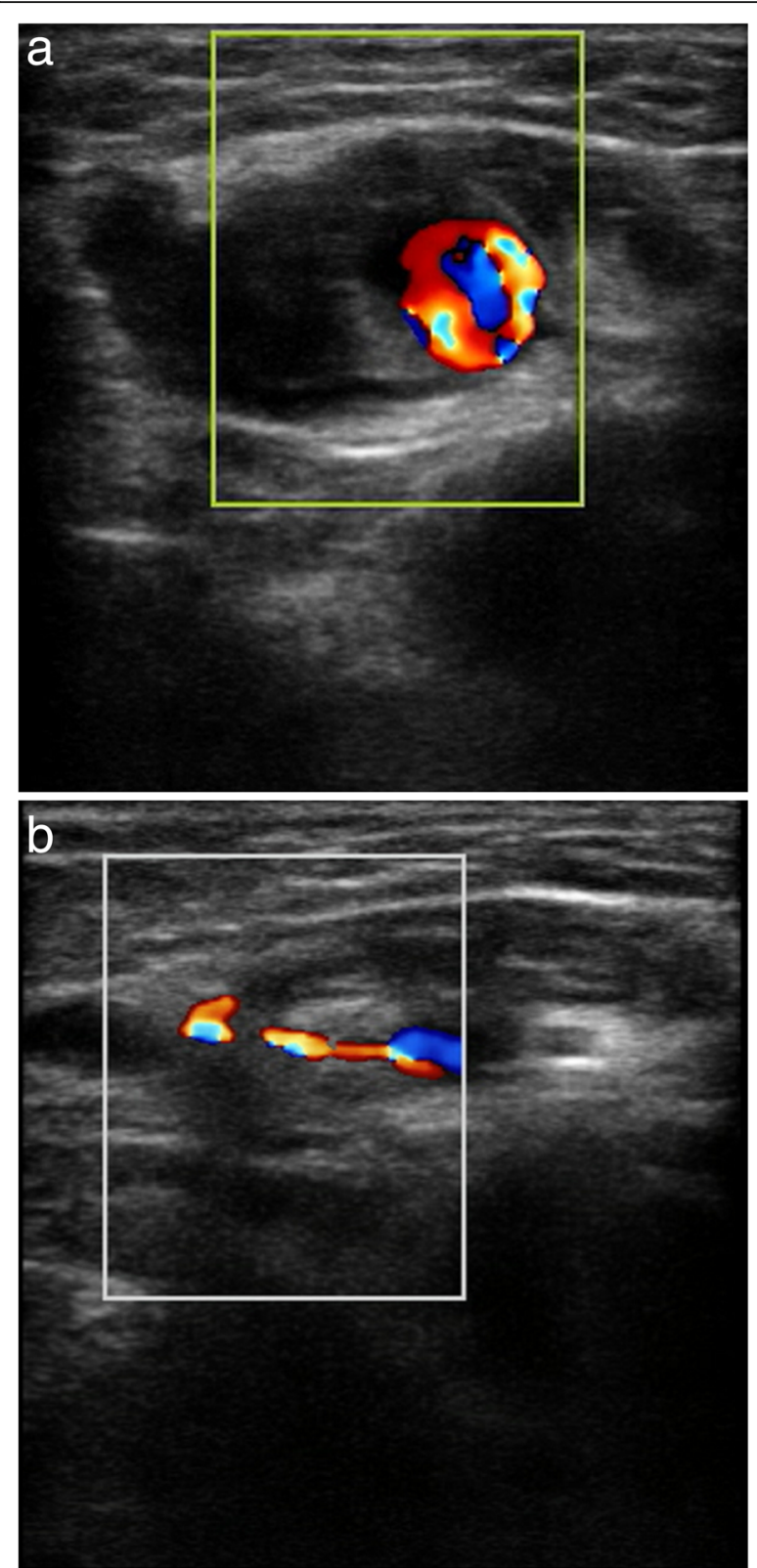

Fig. 3 Doppler ultrasonography over the posteromedial aspect of the left knee. a A well-defined mass with bidirectional flow was shown. $\mathbf{b}$ The size of the mass decreased under compression with the ultrasound probe

branch of the deep femoral artery, and the medial inferior genicular artery [9-13]. Vincent et al. described a pseudoaneurysm at the saphenous branch of the descending genicular artery after arthroscopic meniscectomy, which was caused by accessory medial portal construction and treated with ligation [14]. To the best of our knowledge, no report has been published regarding pseudoaneurysm at the saphenous branch of the descending genicular artery following arthroscopic ACL reconstruction. 


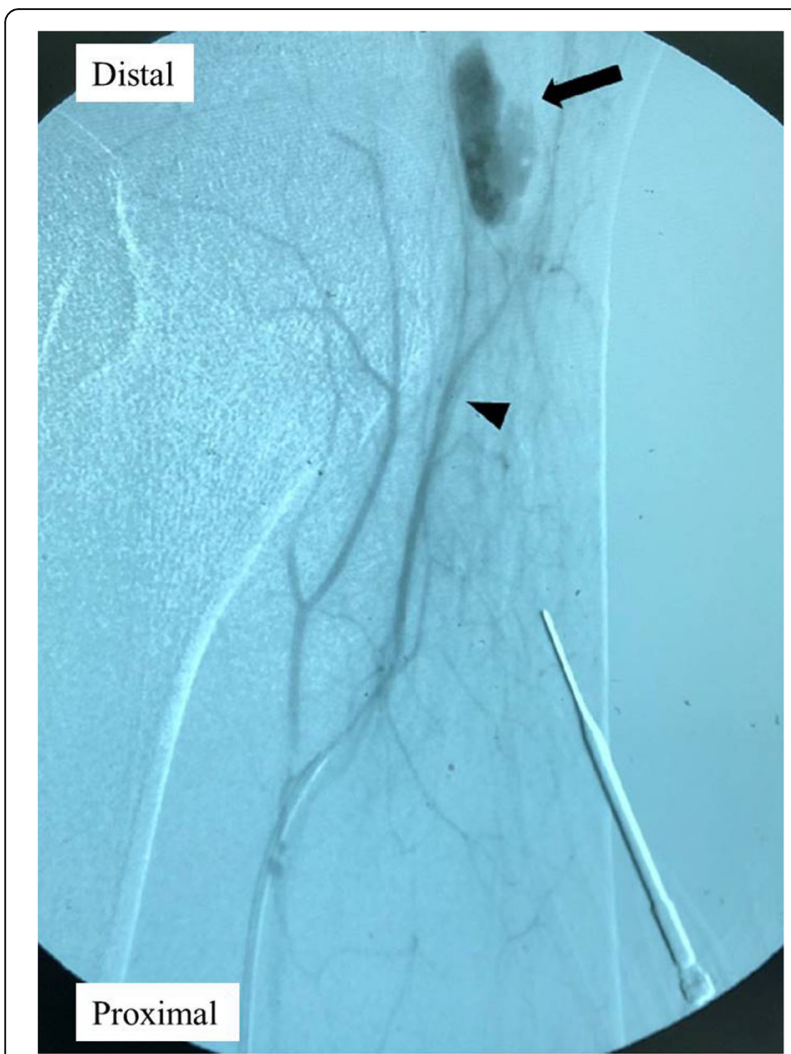

Fig. 4 Diagnostic angiography of the left knee. A pseudoaneurysm with active extravasation (black arrow) was noted adjacent to the saphenous branch of the descending genicular artery (black arrowhead)

We believed that the saphenous branch of the descending genicular artery was traumatized during tendon harvest. Several thick fascial bands pass between semitendinosus and gracilis and also from these hamstring tendons to gastrocnemius, popliteal, pretibial, and superficial fascia [15]. Identifying and dividing these structures to avoid premature tendon amputation and short graft are crucial. The saphenous branch of the descending genicular artery generally passes in a posteromedial location between sartorius and gracilis and crosses the medial joint line in an approximately vertical direction [16]. Its close anatomical proximity to the targeted tendon autograft produces certain risk of vascular injury while dissecting the expansions (Fig. 6).

Advancing the opened scissors proximally in a blind fashion is arguably the most dangerous maneuver in this technique. Also, pushing a closed end tendon stripper with an inappropriate direction not following the hamstring trajectory may cause unwanted shear force on the surrounding vessels. Minor injury to arterioles could be easily neglected during the procedure because vessel retraction under inflated tourniquet results in minimal bleeding [17]. In addition to surgical injury, the underlying

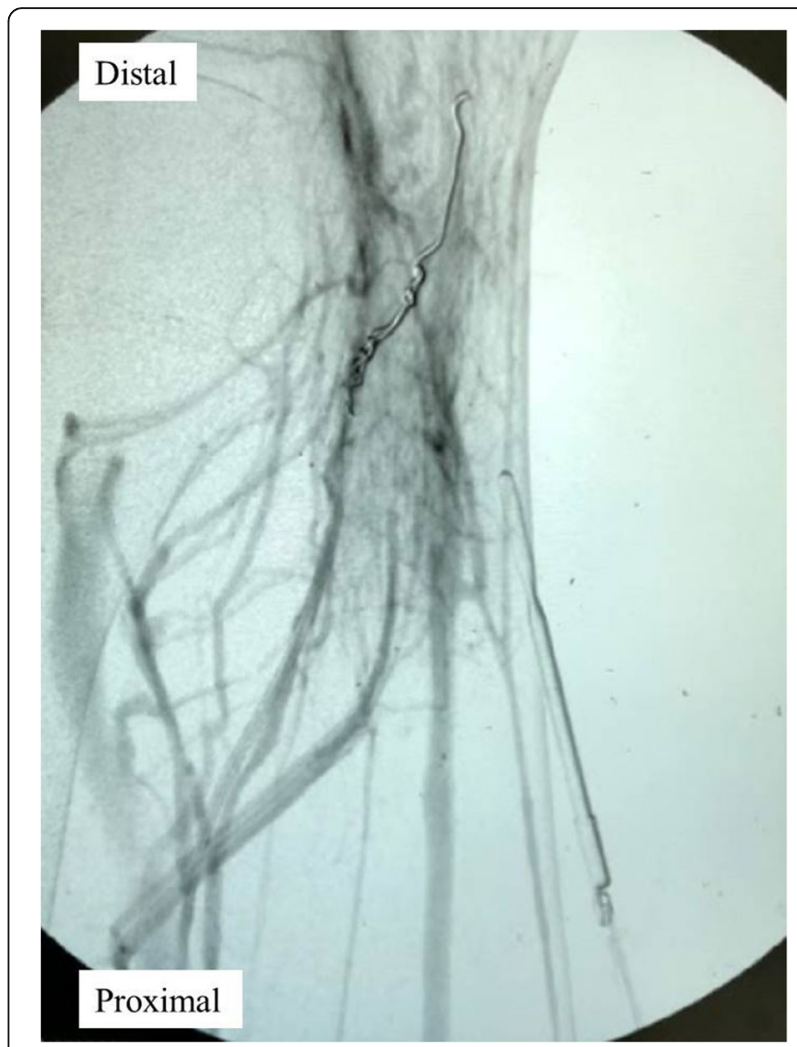

Fig. 5 Post-embolization angiography of the left knee. The pseudoaneurysm was devascularized after placement of two microcoils (TORNADO 3-2 mm, Cool Medical)

disease of patients such as atherosclerotic peripheral vascular disease and bleeding diathesis makes them susceptible to pseudoaneurysm formation [4]. Regarding the history of frequent and copious epistaxis in our case, it is suggestive of a bleeding tendency and a higher chance of developing vascular complication in spite of his normal coagulation studies.

The reported vascular complication does not only concern ACL reconstruction but generally the hamstring tendon harvest in any surgical procedure. It is preferred to reveal and divide the fascial bands one after the other under visual control by pulling on the targeted tendons [18]. Endoscopic harvest technique has been described by Yeh et al. demonstrating a clearer assessment of more proximal fascial and accessory bands and neurovascular structures [19]. More careful hemostasis throughout the surgery is warranted. Deflating the tourniquet before wound closure may help alert the possibility of vascular injury. Intra-arterial interventions enable precise treatment to a more complex and difficult pseudoaneurysm at deep feeding vessels [4]. The sufficient anastomosis around the knee allows embolization without risk of skin or tissue necrosis. 


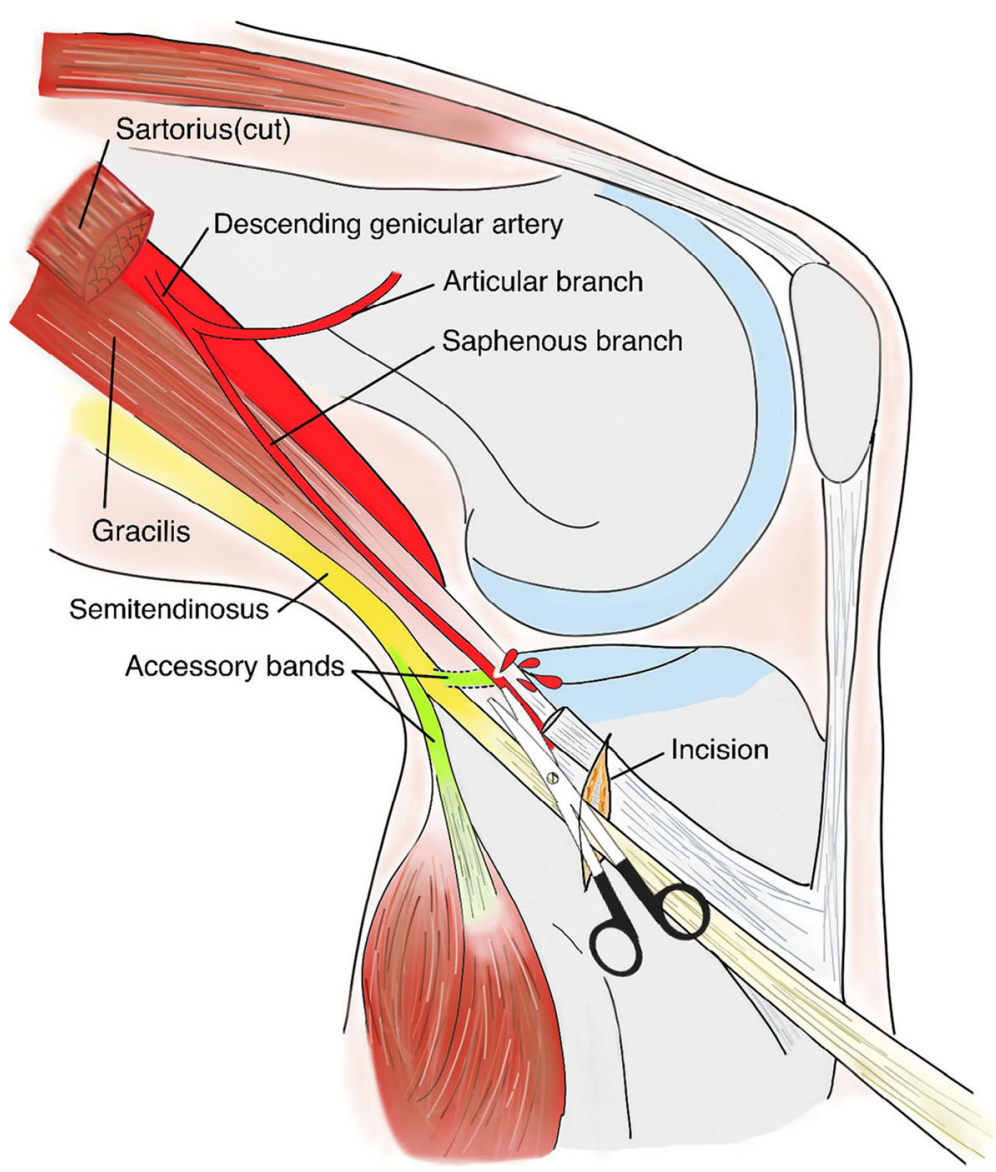

Fig. 6 Illustration of the mechanism of vascular injury. The saphenous branch of the descending genicular artery was damaged when the expansions of semitendinosus were sectioned with opened scissors

In conclusion, although vascular injury rate remains very low in arthroscopic knee surgeries, the possibility of pseudoaneurysm formation at the saphenous branch of descending genicular artery during tendon harvest should not be overlooked. Care must be taken to section the expansions of the hamstring tendon, especially when the patient presents with underlying coagulopathy or vascular disease. Coil embolization has been an effective treatment option to the pseudoaneurysm at terminal branches.

\section{Abbreviation}

ACL: Anterior cruciate ligament

\section{Acknowledgements}

The authors would like to thank Surgical Assistant Hui-Hsuan, Ting for intraoperative assistance, and Physician Assistant Yu-Hsun, Hsu and Yen-Hsin, Kang for patient care and clinical follow up.

\section{Authors' contributions}

$J \mathrm{LW}$ and $\mathrm{CHL}$ contributed to the study conception and design. SHW and CYL performed material preparation and data collection. CWH and SHL drafted the manuscript. All authors read and approved the final manuscript.

\section{Funding}

The authors received no specific grant for this research from any funding agency in the public, commercial or not-for-profit sectors.

\section{Availability of data and materials}

Data sharing is not applicable to this article as no datasets were generated or analyzed during the current study.

\section{Ethics approval and consent to participate}

Approval was granted by the Joint Institutional Review Board of Taipei Medical University Hospital (No. 202003028)

\section{Consent for publication}

Written informed consent was obtained from the patient for publication of this case report and any accompanying images. A copy of the written consent is available for review by the Editor of this journal.

\section{Competing interests}

The authors declare that they have no competing interests.

\section{Author details}

'Department of Orthopedics, School of Medicine, College of Medicine, Taipei Medical University, Taipei, Taiwan. ${ }^{2}$ Department of Orthopedics, Taipei

Medical University Hospital, Taipei, Taiwan. ${ }^{3}$ Department of Medical Imaging, School of Medicine, College of Medicine, Taipei Medical University, Taipei, Taiwan. ${ }^{4}$ Department of Medical Imaging, Taipei Medical University Hospital,

Taipei, Taiwan. 
Received: 6 July 2020 Accepted: 14 October 2020

Published online: 21 October 2020

\section{References}

1. Sanders TL, Maradit Kremers H, Bryan AJ, Larson DR, Dahm DL, Levy BA, et al. Incidence of anterior cruciate ligament tears and reconstruction: a 21year population-based study. Am J Sports Med. 2016;44(6):1502-7.

2. Stewart BA, Momaya AM, Silverstein MD, Lintner D. The cost-effectiveness of anterior cruciate ligament reconstruction in competitive athletes. Am J Sports Med. 2017:45(1):23-33.

3. Grossman MG, ElAttrache NS, Shields CL, Glousman RE. Revision anterior cruciate ligament reconstruction: three- to nine-year follow-up. Arthroscopy. 2005;21(4):418-23.

4. Sadat U, Naik J, Verma P, See TC, Cousins C, Chitnavis JP, et al. Endovascular management of pseudoaneurysms following lower limb orthopedic surgery. Am J Orthop (Belle Mead NJ). 2008;37:E99-E102.

5. Janssen RP, Scheltinga MR, Sala HA. Pseudoaneurysm of the popliteal artery after anterior cruciate ligament reconstruction with bicortical tibial screw fixation. Arthroscopy. 2004;20(1):E4-6.

6. Joshi A, Singh N, Pradhan I, Basukala B. Pseudoaneurysm of the popliteal artery leading to foot drop after arthroscopic anterior cruciate ligament reconstruction: a rare complication: a case report. JBJS Case Connect. 2019; 9(4):e0481

7. Tam Kelvin K-W, Wun Y-C, Lau C-Y, Chow Y-Y. Pseudoaneurysm of the popliteal artery after anterior cruciate ligament reconstruction surgery: a case report and literature review. J Orthop Trauma Rehabil. 2014;18(1):44-6.

8. Xu D, Ji L, Zhu J, Xie Y. Popliteal pseudoaneurysm and arteriovenous fistula after arthroscopic anterior and posterior cruciate ligament reconstruction: a case report. Int J Surg Case Rep. 2017;40:50-3.

9. Evans JD, de Boer MT, Mayort P, Rees D, Guy AJ. Pseudoaneurysm of the medial inferior genicular artery following anterior cruciate ligament reconstruction. Ann R Coll Surg Engl. 2000;82:182-4.

10. Fujii M, Furumatsu T, Kadota Y, Shimamura Y, Tsuchimochi S, Ozaki T. Pseudoaneurysm of the perforating branch of the deep femoral artery following anterior cruciate ligament reconstruction. Acta Med Okayama. 2016;70(6):515-8

11. Mello W, de Brito WE, Migon EZ, Borges A. Pseudoaneurysm of the medial inferior genicular artery after anterior cruciate ligament reconstruction. Arthroscopy. 2011:27(3):442-5.

12. Milankov M, Miljkovic N, Stankovic M. Pseudoaneurysm of the medial inferior genicular artery following anterior cruciate ligament reconstruction with hamstring tendon autograft. Knee. 2006;13(2):170-1.

13. Tsubosaka M, Matsushita T, Kuroda R, Matsumoto T, Kurosaka M. Pseudoaneurysm of the articular branch of the descending genicular artery following double-bundle anterior cruciate ligament reconstruction. Knee Surg Sports Traumatol Arthrosc. 2017;25(9):2721-4.

14. Vincent GM, Stanish WD. False aneurysm after arthroscopic meniscectomy A report of two cases. J Bone Joint Surg Am. 1990;72(5):770-2.

15. Candal-Couto JJ, Deehan DJ. The accessory bands of Gracilis and semitendinosus: an anatomical study. Knee. 2003;10(4):325-8.

16. Tozzi A, Ferri E, Serrao E, Colonna M, Marco PD, Mangialardi N. Pseudoaneurysm of the descending Genicular artery after arthroscopic Meniscectomy: report of a case. J Trauma Inj Infect Crit Care. 1996;41:340-1.

17. Manning MP, Marschal JH. Aneurysm after arthroscopy. J Bone Joint Surg Br. 1987;69:151

18. Lanternier $\mathrm{H}$, de Cussac JB, Collet T. Short medial approach harvesting of hamstring tendons. Orthop Traumatol Surg Res. 2016;102(2):269-72.

19. Yeh W-L, Chen J-M, Liu C-H, Tsai P-J, Higashiyama R, Takaso M. Endoscopic harvest of autogenous Gracilis and semitendinosus tendons. Arthroscopy Techniques. 2018;7(10):e1019-e24.

\section{Publisher's Note}

Springer Nature remains neutral with regard to jurisdictional claims in published maps and institutional affiliations.

Ready to submit your research? Choose BMC and benefit from:

- fast, convenient online submission

- thorough peer review by experienced researchers in your field

- rapid publication on acceptance

- support for research data, including large and complex data types

- gold Open Access which fosters wider collaboration and increased citations

- maximum visibility for your research: over $100 \mathrm{M}$ website views per year

At $\mathrm{BMC}$, research is always in progress.

Learn more biomedcentral.com/submissions 